\title{
Re-examining the Role of Knowledge within Planning Theory
}

\begin{abstract}
While modernist planning theory reifies knowledge as an object and makes it an inherent part of modernism's legitimacy, postmodern planning theory celebrates multiple epistemologies but fails to specify institutional arrangements for handling multiple knowledges in a way that recognises the specificity of knowledge claims. An argument is made here for the limited variety of forms that such knowledge claims can take and the need to create spaces within planning processes for testing and recognising these different knowledge claims.
\end{abstract}

Yvonne Rydin

Department of Geography and Environment

LSE

Houghton Street

London

WC2A 2AE

Tel: 02079557605

Fax: 02079557412

Email: Y.Rydin@1se.ac.uk

Yvonne Rydin is Professor at the Bartlett School of Planning, University College London 


\section{Re-examining the Role of Knowledge within Planning Theory}

\section{Introduction}

There has been a significant shift in the conceptualisation of the category of 'knowledge' within the social sciences over recent decades. Latour discusses this in terms of the breakdown of the modernist consensus (1999). This consensus had seen the Enlightenment dilemma of a dualism of nature and society resolved by knowledge providing a mirror onto 'nature' for 'society'. Knowledge was an entity, to be held and used. It was produced by experts in distinct institutions through processes that ensured its objectivity. The breakdown of this consensus involved recognising that knowledge is constructed through social processes and that the institutions that generate knowledge will not necessarily ensure neutrality (Irwin, 1995). More generally, it involved seeing knowledge not as an object but as embedded in sets of social relations (Wynne, 2002). Knowledge is therefore generated in knowledge networks encompassing sets of relevant linkages. In policy contexts, bounded networks such as epistemic communities (Haas 2001, 2004) or communities of practice (Wenger, 1998) operate to construct knowledge in processes that involve scientific experts and practitioners.

This shift has implications for the social process of planning. As Sandercock explains, planning as an activity has its roots in a modernist conception of society (1998). As such, it has been based on a belief in planners' ability to manage events in pursuit of the greater public good. The use of knowledge is a central element in achieving change through planning. Indeed the very rationale for planning within modernism is 
that knowledge can be harnessed through planning to achieve positive change. The notion of progress is inherent to modernism so that as knowledge accretes over time, societal improvement follows from the use of more and better knowledge through planning. Planning practice has, therefore, seen itself as a user of knowledge in the pursuit of progress. The status of planners as experts resides in their command of specialist knowledge.

The critique of modernist planning offered by contemporary planning theory raises key issues for how knowledge should be conceptualised within the planning process and how, institutionally, arrangements should be put into place for handling knowledge within that process. This is the focus of this paper - the institutional arrangements concerning knowledge within planning processes. The paper begins by briefly reviewing the emphasis within both the planning theory and sociology of scientific knowledge literatures on multiple knowledges. It argues that the conclusions of these literatures, on the use of deliberative processes as a way of handling multiple knowledges, are inadequate. Instead the paper argues for a pragmatic approach to knowledge, which focuses on creating arenas for the testing and recognition of knowledge claims within planning processes. It discusses the importance of testing knowledge claims and briefly sets this in the context of Habermas' discussion of validity claims and communicative action. Finally, it presents a heuristic typology of knowledge claims within planning and discusses the institutional arrangements involved in claim testing and recognition using three planning examples. These examples demonstrate the importance of the explicit consideration of knowledge in a post-modern planning era. 
Before proceeding, it is useful to define terms. Knowledge differs from information and data in that the specification of a causal relationship is central to knowledge. This is why knowledge is of such central relevance to planning. Since planning seeks to create specific impacts, planners need to understand how such impacts follow from specific planning actions; they need to understand the causal relationships between action and impact. Causal relationships may be implicit in the presentation of a particular dataset or type of information, but in that case it is the knowledge that supports the use of that data or information that is important. This paper argues for the more explicit recognition that knowledge of such causal relationships is an important part of planning practice and then works through the institutional implications of such a recognition.

\section{From knowledge to knowledges}

One of the implications of the breakdown in the modernist consensus on knowledge has been the call from the sociological literature on science, the policy literature on environmental issues and the planning theory literature that knowledge can no longer be considered as a unified category (Evans and Marvin, 2006). Knowledge is inherently multiple, with multiple claims to representing reality and multiple ways of knowing (Sandercock, 1998). This is in contrast to the positivist claim of modernism that examination of the facts will reveal the truth. Closely associated with this insight is the argument that knowledge is not just the domain of the expert - whether a scientist or a planner - but rather is associated with a variety of actors in a variety of social locations. Knowledge now has a variety of sources and takes a variety of different forms. 
Within science studies, there has been an emphasis on exploring how scientific knowledge needs to engage with lay knowledges (Wynne,1996). The environmental domain has particularly demonstrated the benefits of engaging with local people, who live and work in close relationship with their physical environment (such as agrarian communities) and have developed knowledge of that environment through their everyday experience. This is local, experiential and contextualised knowledge, as compared to the non-local, objectified and generalised knowledge of scientific institutions. While some have argued against the automatic prioritisation of local over scientific knowledge (Forsyth, 2002), it is now generally accepted that the knowledge embedded in local relationships needs to be drawn upon in local policy practice, to guide the contextualisation of conventional scientific knowledge. This can be distinguished from more general calls for the involvement of the public in debating scientific issues and their public policy applications, where the aim is to engage scientific communities with social values and thereby engender greater public acceptance of and trust in particular policy approaches (Owens, 2000).

A parallel trend can be seen within planning theory. As readers of this journal well know, planning theory has been on a journey over the last half-century from the exposition of an essentially modernist conception of planning - perhaps reaching its peak in the systems theory of the 1970s - to a more fragmented theoretical field (Allmendinger, 2001, 2002). Within this current theoretical fragmentation there are signs of a new orthodoxy emerging. This new orthodoxy clusters around the idea that the core of planning should be an engagement with a range of stakeholders, giving them voice and seeking to achieve a planning consensus. For theorists and 
practitioners of consensus building, this consensus has to be won through negotiation and mediation between interests (Innes, 2004); for collaborative planning theorists (Healey, 1997), consensus is potentially inherent in the act of communication between stakeholders; for radical planners (Sandercock, 1998), the aim is not consensus at any price but empowerment of the most disadvantaged and unheard within society.

What is of interest to the theme of this paper is the view of knowledge implied in this new orthodoxy. The shift from the modernist model challenges the notion of the planner as the knower, the holder of knowledge (Sandercock 1998, p. 88). Instead, contemporary planning theory - in line with contemporary science studies - puts considerable emphasis on knowledge being held outside the planning organisation and by groups other than professionally trained planners. Sandercock herself calls for 'an epistemology of multiplicity' (op. cit. p. 76) encompassing the following ways of knowing: through dialogue; from experience; from local knowledge; by learning to read symbolic and non-verbal evidence; and through contemplative or appreciative knowledge. In this vision, planning is transformed by seeking knowledges in new forms and having a heterogeneous knowledge base for its actions.

But more than this, the purpose of planning is to handle multiple knowledges. The emphasis is on listening to unheard voices and hence previously unheard knowledges variously categorised as lay, local, experiential or intuitive. The difficulty that this poses for planning is how to handle the multiple sources of knowledge, how to engage different knowledges with each other and how to change decision making as a result. The answer that has emerged - again from sociology of science, environmental policy and planning theory literatures - is a greater reliance on deliberative and collaborative 
approaches. But there are a number of concerns with this reliance on deliberation and collaboration.

\section{Knowledge and the limits to deliberation and collaboration}

Some concerns are general to the use of deliberative and collaborative processes within planning. These have been well-rehearsed (Tewdwr-Jones and Allmendinger, 1998; Flyvbjerg, 1998; Rydin, 2003a) and can be summarised as: a lack of specificity as to how the theory of these processes should put into practice; doubts as to the abilities of planners to undertake such processes successfully; the potential for powerful interests to subvert the processes; and the inability of such processes to handle conflicts of interests and generate a consensus or agreement in the face of such conflicts. However, there are specific concerns regarding the use of such processes to handle multiple knowledges (see also Petts and Brooks, 2006). After all, such processes are usually promoted on the basis of exploring the values of local communities and generating trust between parties. The orientation towards reaching agreement (if not actual consensus) may not be best-suited to ensuring that the most appropriate knowledge influences decision-making. There are two aspects to this: whether such processes can handle multiple knowledges; and whether they are able to distinguish knowledge from other bases for involvement.

Handling multiple knowledges involves more than just bringing the different actors together to articulate those knowledges in a context oriented towards mutual understanding. Just as with other heterogeneous voices, the engagement between multiple knowledges - particularly lay and expert knowledges - involves translation. 
But, as Evans and Marvin (2006) warn us, knowledges are not additive and so reducing them to a lingua franca will not of itself enable a resolution to that engagement. It is much more difficult than often acknowledged to generate agreement between actors whose knowledge of an issue is rooted in very different experiences. In a recent clarification of one version of the collaborative paradigm, Innes points out that consensus building does not proceed through the force of better argument but rather by collective story telling (2004). She identifies two rather different conditions in which consensus building can make a positive contribution: on the one hand, accessible and fully shared information is cited as one of a set of preconditions for this approach (p. 7); on the other, it is seen as appropriate in conditions where 'uncertainty is rampant' (p. 16). In both cases, the emphasis falls on values and understandings, either because there is no dispute over knowledge or there is no certain knowledge. However most planning situations fall between these extremes.

It is therefore necessary to acknowledge that engaging different knowledges is fundamentally different to engaging different voices. To explore this, it is helpful to recast knowledge as knowledge claims, i.e. a claim to understanding certain causal relationships. A variety of claims are asserted within planning processes, but a knowledge claim can be distinguished from an ethical, pragmatic, efficiency or aesthetic claim, say. All such claims are important within a planning process; but they are different from each other. As Collins and Evan say, in an important exchange in science studies, stakeholder rights are conceptually different from rights based on expertise (2002, p.250; see also Jasanoff, Rip and Wynne, 2003). This is a point that Habermas argued through his tripartite structure of speech acts in terms of validity claims: claims to truth, normative legitimacy and truthfulness. These are constituted 
in the form of constatives, regulatives and expressives respectively in his terminology and are seen as distinct aspects of speech acts (1987, p. 121; Niemi, 2005).

Planning processes therefore need to be able to distinguish knowledge claims put forward by actors from the other kinds of claims that actors may make. This is not to say that the knowledge claims are more important than, say, the ethical claims but rather they are fundamentally different. This point has been somewhat obscured within contemporary planning theory for two reasons. First, there has been an emphasis on values and how to generate a social agreement from a mix of different values. There are values implicit in knowledge claims but knowledge cannot be reduced only to the associated values. Second, there has been a tendency to label all the claims of local communities in particular as forms of knowledge (see Sandercock, 1998). Given the emancipatory message in much planning theory, there is a political rationale in describing the claims of civil society stakeholders in this way; talking of such actors as having knowledge raises their status within the planning process. The experience of local stakeholders may be an important basis for claiming local or experiential knowledge but, as Collins and Evans point out, such experience is not of itself a sufficient condition for it to be knowledge (2002, p. 251; see also Rip, 2003, p. 424).

A few examples may clarify this point. In the case of an environmental risk, a distinction is often drawn between expert quantitative and/or probabilistic assessment of risk and a local communities' attitude to that risk. Accredited experts can present the latter as exaggerated and based on insufficient information or understanding. Proponents of a more participatory approach, however, have argued that the 
communities' perspective is as relevant as an experiential account of that risk. In some cases, that experience (for example, of local ill-health episodes) may form the basis for challenging prevailing expert assessments. But that does not mean that all community perceptions of environmental risk are knowledge. Turning to issues of cultural heritage, local communities may have historic knowledge about their locality that could contribute to planning practice. The community probably also have an emotional attachment to the locality and further political claims based in their historical stake in the area. Their knowledge claims may be important in generalising the community's overall claims to direct the future of their area but they are distinct from the emotional and historic claims. Finally, a socially disadvantaged community can provide rich knowledge about their lived experience that could highlight previously overlooked problems of poverty. This knowledge could shape the details of regeneration strategies. Such communities also have a powerful ethical claim to influence local planning but the ethical and knowledge claims are not coincident.

\section{Planners as co-producers of knowledge}

Highlighting the role of planning institutions in relation to knowledge claims also means that role of the planning system in co-producing knowledge can be acknowledged (Jasanoff, 1990). This is in line with the argument for the emergence of a new mode (Mode 2) of knowledge production in which practitioners and users are actively involved in the production of knowledge (Gibbons, et al., 1994). This coproduction work is of two kinds. First, following through on the insights of contemporary planning theory, there is the work of giving voice to the various actors who have a knowledge claim relevant to the issue at hand; in doing so, planners need 
to recognise the position of more and less powerful actors. But, taking the argument beyond this body of theory, planners can also be actively involved in recognising some of these claims as knowledge claims relevant to planning practice, and this involves some degree of testing of the claims. In the debates within science studies, a renewed emphasis on the testing of different knowledge claims has been seen as key to reconciling the insights of lay and expert knowledges.

Liberatiore and Funtowicz argue:

Expertise is not found but made in the process of litigation, decision-making and public debate; at the same time, not all knowledge claims are to be treated as equal. Expertise has legitimacy when it is exercised in ways that make visible its contingent, negotiated character and other critical views are accepted. (2003, p. 149, my emphasis)

In the debate on Collins and Evan's paper, Rip refers to the need for 'assessing the robustness of the knowledge being produced' (2003, p. 422); Nowotny sets out some criteria for 'socially robust knowledge': tested for validity, involving an extended group of experts, and repeatedly tested, expanded and modified (2003, p. 155). Jasanoff sees a key purpose of more participatory processes to test expertise and hold it to 'cultural standards for reliable public knowledge' (2003, p. 397-8).

Rather than being at odds with the Habermasian roots of collaborative planning theory, there are strong connections since Habermas sees the illocutionary acts of speech as necessarily involving validity claims if they are to constitute communicative action: 
'Not all illocutionary acts are constitutive for communicative action, but only those with which speakers connect criticisable validity claims' (Habermas, 1984, p. 305).

His argument is that consensus through communication depends on the speaker being able to convince her listener(s) that the claims are rational and thus worthy of recognition (White, 1988, p. 28). Rationality here involves justifying the claims with reference to the appropriate criteria. In the case of constatives the reference point is factual material, for regulatives established norms and for expressives authenticity.

The mutual expectation of those engaged in communicative action is that a validity claim can, if challenged, be defended and this creates a 'binding force' between actors (ibid, p. 34). Thus a speech act needs to be mutually understandable (the point that has been most emphasised within planning theory) but also warranted, i.e. seen as capable of rational defence (ibid, p. 41). White (1988, p. 42) argues that Habermas overstates this point and that 'in pluralist societies, hearers can understand symbolic expressions without taking a stance on its validity'. But even if this is true for general social interaction, in a planning context, the requirements of rationality would approach Habermas' expectations and that actors are less likely (and should be less likely) willingly to accept validity claims on an unwarranted basis. The interesting point to take from Habermas is that testing of validity claims is seen as an intuitive skill of competent speakers and thus available within communicative arenas. Ironically this intuitive skill is itself a result of the historic conditions of modernity.

This suggests that the planning system should be conceptualised as a series of arenas in which a variety of knowledges engage with each other, with planners not just 
responsible for procedural aspects of the engagement but more actively involved in the co-generation of knowledge through testing and recognising knowledge claims. There needs to be space for giving voice to these various claims-opening-up - but also for testing and ultimately recognising these claims-closing-down.

Contemporary planning theory has tended to be better at discussing opening-up than closing-down. However, if it is recognised that there is a difference between a knowledge claim that stands up to close examination and challenge and one that does not (Collins and Evans, 2002), then there is scope for discussing closing-down. This fits with developments in science studies that see knowledge as both socially constructed and the result of an engagement with material reality (Latour, 1999); this has been variously termed co-construction (Murdoch, 2001), heterogeneous constructionism (Demeritt, 2001) or realist constructivism (Wynne, 2002).

Making spaces within the planning system for debating and testing knowledge claims may involve supporting some actors who do not have the resources to engage in such debates otherwise (see Reardon, 2003 for a very telling example); it will involve understanding that knowledge claims can be expressed in different languages so that accredited expertise is not privileged because it is assumed to talk the language of knowledge. In this, shifting the focus towards knowledge claims still retains the lessons of collaborative or radical planning theory. But it is patronising to assume that knowledge debates cannot be ventured openly in a variety of languages and that lay discourses must necessarily be limited to experiential stories or emotional realms which are somehow knowledge-free or can only be seen as knowledge by expanding the knowledge category; (Collins and Evans refer to this as the 'Problem of Extension', 2002). 
How planning performs this recognition function depends on the kind of knowledge at issue. To explore this further, it is helpful to have a framework for identifying the different kinds of knowledge claims that planners are faced with. The institutional arrangements for responding to these claims can then be specified more fully. This approach is developed below through a typology of knowledge claims and illustrated with three planning policy examples.

\section{A typology of knowledge claims within planning}

While there are always simplifications and limitations involved in the use of typologies, there are also benefits of clarification. So this section proposes to address the question of how to understand the different kinds of knowledge claims by developing such a typology (Collins and Evans, 2002). The case made here starts from a generic concept of planning, one with an acknowledged normative focus based in the desire to achieve an improved natural and built environment for society. Beyond this the model does not seek to specify a planning approach more tightly.

$\underline{\text { Insert Figure } 1 \text { and Table } 2 \text { near here }}$

Figure 1 sets out the starting point for the discussion. In Figure 1, planning seeks to turn State A into State $\mathrm{B}^{1}$. In the absence of planning, then societal, economic and environmental processes would result in a transformation of State A to State B. This does not mean that planning is somehow seen as outside of such societal, economic and environmental processes; on the contrary, it is clearly constituted by such processes. However, the discussion seeks to identify the particular contribution 
that a planning process is trying to make. Neither does this admittedly simple formulation seek to deny the complexity of society and of planning's engagement with that complexity. Rather it seeks to capture the essence of what a planning action is trying to achieve and this is a change in the nature of the physical (natural and built) environment.

However, planning outcomes may well differ from stated planning intentions. Contemporary planning commentators and practitioners no longer take it for granted that they will end up where they say they are going; $\mathrm{B}^{1}$ can be an elusive goal. Nevertheless the intervention of planning has some effect, even if not the stated one. Some have argued that the impact of planning is a purely symbolic one, with no real effect on the physical environment (Ball 1983, Ambrose 1986). But these views are overwhelmed by research on the impact that planning does have, highly critical though much of this research is (see Rydin 2003b, Ch.14 and Ward 2004, Ch. 10 for a review of such research). So Figure 1 also identifies State $B^{2}$ as the state resulting from the intervention of planning. If $B$ is the anticipated housing shortage and $\mathrm{B}^{1}$ is the planned matching of housing supply and housing need, then $\mathrm{B}^{2}$ is the combination of profitable housing developments with continuing over-crowdedness, housing stress and homelessness.

The value of Figure 1 lies in the categorisation it offers of the different ways that knowledge claims could be relevant to the planning process:

1. Knowledge of the current State A can act as a benchmark against which a preferable State $\mathrm{B}^{1}$ can be measured.

2. Knowledge of the predicted State B represents a refinement of the first kind of knowledge, recognising that society is not static but moving 
towards new patterns, so that desired planned state $\mathrm{B}^{1}$ must be judged against State B, not A. Such knowledge of State B requires, in turn ...

3. Knowledge of the social, economic and environmental processes that will move us from State A to B.

4. Given the knowledge about a desired State $\mathrm{B}^{1}$, this implies a need for further process knowledge, that linking State A to State $\mathrm{B}^{1}$. This is knowledge of the planning process itself and how it could work to achieve desired ends. However, in keeping with the recognition that planning practice does not (always) achieve these ends, two further types of knowledge can be identified ...

5. Knowledge of the actual outcomes of planning processes in their societal context, i.e. of State $\mathrm{B}^{2}$ and ...

6. Process knowledge of how State A was turned into State $\mathrm{B}^{2}$.

This suggests, therefore, six different types of knowledge: two broadly empirical and descriptive, one predictive, and three process-oriented.

However, there is also a kind of knowledge involved in specifying the goal of planning. In this model, the goal of planning is desired State $\mathrm{B}^{1}$ and the specification of this itself requires a form of knowledge, knowledge of possible futures. But this kind of knowledge is different from both the more empirical and process knowledges outlined above. Knowledge of desired states is explicitly normative in character; indeed its normative character defines the type of knowledge. Hence this type of knowledge could be called normative. This is not to deny that empirical descriptions and analyses of processes are both inherently value-laden. The choice of descriptors of a state and the emphasis on certain causal dynamics carry with them value judgements. But the desired state is prioritised as normative. It is not exclusively 
normative though - and it is here that its character as a form of knowledge lies - since not any imaginings will serve as a planning goal. There has to be an engagement with possible realities and therefore this form of knowledge is both explicitly normative and yet still based in claims about possible paths. So the following can be added to the list:

7. Normative knowledge of State $B^{1}$

Each of these knowledge types plays a distinctive role within planning and each has rather different characteristics (see Table 1 for the application of this typology). But despite the differences between these types of knowledge claims, there are common features. First, none of these knowledges can be considered value-free. In each case there are value judgements involved in the framing of the knowledge, the decision as to what is the object of knowledge. In descriptive knowledge, something specific has to be described and that selection is value-laden. It makes a difference if market prices or child poverty is used to describe the affluence of an area. Second, each knowledge category is not only reflective of values but also carries with it a related causal story. This may be more implicit (as with many statements of descriptive knowledge) or acknowledged explicitly (as with some statements of predictive or process knowledge) but all knowledge has a causal story embedded within it.

\section{Testing and recognising knowledge claims within planning}

The challenge this poses to planning practitioners is to create arenas to engage, test and recognise these different knowledge claims. Rip talks of 'hybrid forums' for 'agonistic, collective learning' and sees the important next step as being 'to look into 
the (emerging and/or designed) arrangements that are conducive to agonistic, learning and robust outcomes' (2003, pp. 425-7). There are a number of important institutional issues: how is the knowledge to be generated; what are the roles of the planner and researcher; how is testing to be handled? These governance concerns are summarised in Table 2, where the seven varieties of knowledge are collapsed into four types: empirical, process, predictive and normative. The three planning policy examples of Table 1 are again used as illustrations in the discussion below.

Taking empirical knowledge claims first, the above discussion has highlighted that such knowledge can come in lay as well as expert forms. Hence the term experiential knowledge may also be appropriate. As the knowledge will be based in lay and/or expert engagement with material circumstances, a variety of research methods will be appropriate and these will also find expression in a variety of ways. A community report on the experience of living in a village will be different to an expert assessment of the quality of life or natural capital in that village. The planner will have to respond to this by taking a number of roles. In commissioning evidence of these empirical states, there is a tendency to a consultancy model with the planner acting as client. Or the planner may take the role of amassing and analysing data. Or s/he will be facilitating the participation of local communities in making their knowledge explicit and presenting it in an appropriate form. The planner also plays a key role in handling differences between knowledges, particularly lay and expert positions. This requires forums for engaging expert with expert, lay perspective with lay perspective and lay and expert perspectives in examination of each other's claims. Again the planner may need to support less powerful lay contributors. Any forum also requires procedures for resolution of these multiple claims to establish a relatively uncontested basis for planning action and evaluating that action. 
Turning to process knowledge, this involves theoretically framed investigation of processes, both processes internal to planning organisations and those in the socioeconomic domain. It also involves research on the processes whereby planning engages with those socio-economic processes. This emphasis on processes involving planning practice suggests that in some cases a form of action research may be appropriate, alongside more traditional forms of research. This puts the planner in a very different position in terms of generating knowledge. Their experiential knowledge makes them the object of research but, in the case of action research, they are participants in the research. Lay input may still be relevant and a further role for the planner will be to judge how this input is to be facilitated and managed. Testing process knowledge claims requires the engagement of different causal models. This may take place in the academy but evaluations of policy and practice may also offer such opportunities. Eventually the planner needs to decide if the causal model is sufficiently robust for decision-making purposes.

In the case of predictive knowledge, there are similarities with process and empirical knowledge. What is involved here is theoretically framed investigation of future trends. This tends to be expert-led since lay knowledge tends to be based in current and past experience rather than suited to arguing about future trends. There may, however, be lay evidence that can support investigation of future trends. The role of the planner tends towards a consultancy model in which the planner is the client of the researcher, but one alert to the potential contribution of lay experiences. Testing of knowledge claims is similar to that for process knowledge. In particular it requires appropriate fora for examining challenges to the causal models underpinning predictions; however, there will also be methodological dimensions with debate on techniques of prediction. 
Finally, turning to normative knowledge of appropriate goals for planning, this requires grounding in the range of possibilities for the future. But normative knowledge remains predominantly normative in character and, as such, it must be based in debate in the public sphere where a range of voices can be heard. The academic community (including universities and think tanks, etc.) can play a role through thinking through alternative future scenarios and much politically engaged and normative academic work takes this form. Flyvbjerg has sought to raise the status of such research through his model of social scientific research as phronesis (1992). The role of planner is similar to that proposed within collaborative planning but with an emphasis on the informed nature of the debates that are being managed.

For, while normative debate in general can be open and unbounded, this form of normative knowledge requires that the claim of a future scenario being possible is seen as warranted. It is also important that the planner prevents any possible futures being ruled out of consideration. Here planners are adding an ethical voice of their own, supporting the hope of theorists such as Sandercock that planning can be genuinely emancipatory.

The three planning examples used in Table 1 can illustrate this discussion. For example, in the sustainable construction case there will be an emphasis on expert knowledge of construction practices across the knowledge categories but this needs to be informed by the experiential knowledge of building users and open to challenge from NGOs as to their environmental impact and possible green futures. In the housing market case, while the development industry is a key source of expertise, planners need to be alert to the way that the housing 'problem' is framed through their market-led expertise and incorporate voices that challenge this perspective and suggest alternative visions of how housing need might be met. Alternative academic 
voices may be a support in structuring such debates. Finally, in the landscape values case the planner will be faced with a mix of different assessments of those values, potentially including expert assessment of lay values and those arising from more deliberative processes. Lay knowledge on change in the physical landscape may also be relevant. The challenge will be to engage these different voices, recognising the values and the knowledge that they give expression to.

The typology of planning knowledges therefore supports a variety of types of research activity, a number of different roles for planners in relation to that research and the organisation of forums for handling the different types of testing associated with each type of knowledge. These forums are particularly important since without this challenging activity, knowledge claims lose their specific character as knowledge and run the risk of becoming subsumed into the other types of claims that planning has to contend with.

\section{Conclusion}

This paper has sought to bridge some of the debates between modernist planning theorists and contemporary postmodern planning theory by arguing for the specific contribution of knowledge within planning while still seeing knowledge as socially constructed, multiple and constituted in the form of claims, open to contestation and recognition. This opens the way to rethinking some of the claims of contemporary planning theory about multiple epistemologies, allowing for planning to hear multiple voices in the name of democratic participation and empowerment but also arguing for specific spaces within planning to test out multiple knowledge claims. Not all claims within planning can be recast as knowledge claims just to promote the status of the 
claim-maker. There is a need to assert the value of knowledge within planning alongside the value of hearing diverse stakeholders. The typology of different planning knowledges and the arguments for claims-testing spaces within planning are proposed as ways of overcoming the current divide in the attitude to planning knowledge between the modernists and postmodernists.

\section{Acknowledgements}

I would like to thank the editors of Planning Theory for their patience in letting me develop the ideas in this paper over an extended period and various referees for their helpful comments. 


\section{References}

Allmendinger, P. (2001) Planning in Postmodern Times. Routledge: London.

Allmendinger, P. (2002) Towards a post-positivist typology of planning theory, Planning Theory 1(1), 77-99.

Ambrose, P. (1986) Whatever Happened to Planning? Methuen: London.

Ball, M. (1983) Housing Policy and Economic Power: the political economy of owner occupation. Methuen: London.

Collins, H. \& Evans, R. (2002) The third wave of science studies, Social Studies of Science 32(2), 235-296.

Demeritt, D. (2001) The construction of global warming and the politics of science, Annals of the Association of American Geographers 91(2), 307-337 \& Science and the understanding of science: a reply to Schneider, 91(2), 345-348.

Evans, R. \& Marvin, S. (2006) Researching the sustainable city: three models of interdisciplinarity, Environment and Planning A

Flyvbjerg, B. (1992) Aristotle, Foucault and Progressive Phronesis. Outline of an applied ethics for sustainable development, Planning Theory 7/8, 65-84.

Flyvbjerg, B. (1998) Rationality and Power: democracy in practice. Chicago: University of Chicago.

Forsyth, T. (2002) Critical Political Ecology: the politics of environmental science. London: Routledge.

Gibbons, M. et al. (1994) The new production of knowledge : the dynamics of science and research in contemporary societies. London: Sage.

Haas, P. (2001) Epistemic communities and policy knowledge, International Encyclopedia of Social and Behavioural Sciences, pp. 1157-86. New York, NY: Elsevier. 
Haas, P. (2004) When does power listen to truth? A constructivist approach to the policy process, Journal of European Public Policy 11(4), 569-592.

Habermas, J. (1984) The Theory of Communicative Action Vol. 1 transl. T. McCarthy. London: Heinemann.

Habermas, J. (1987) The Theory of Communicative Action Vol. 2 transl. T. McCarthy. London: Heinemann.

Healey, P. (1997) Collaborative Planning. London: Macmillan.

Innes, J. (2004) Consensus building: clarifications for the critics, Planning Theory $3(1), 5-20$.

Irwin, A. (1995) Citizen Science: a study of people, expertise and sustainable development. London: Routledge.

Jasanoff, S. (1990) The Fifth Branch: science advisers as policymakers. Cambridge, MA: Harvard University Press.

Jasanoff, S. (2003) Breaking the waves in science studies, Social Studies of Science 33(3), 389-400.

Latour, B. (1999) Pandora's Hope: essays on the reality of science studies.

Cambridge, MS: Harvard University Press.

Liberatore, A. \& Funtowicz, S. (2003) "Democratising" expertise, "expertising" democracy: what does this mean and why bother?, Science and Public Policy 30(3), 146-150.

Murdoch, J. (2001) Ecologising sociology: actor-network theory, co-construction and the problem of human exemptionalism, Sociology 35, 111-133.

Nieme, J. (2005) Habermas and validity claims, International Journal of Philosophical Studies 13(2), 227-244. 
Nowotny, H. (2003) Democratising expertise and socially robust knowledge, Science and Public Policy 30(3). 151-156.

Owens, S. (2000) "Engaging the public": information and deliberation in environmental policy, Environment and Planning A 32. 1141-1148.

Petts, J. \& Brooks, C. (2006) Expert conceptualisation of the role of lay knowledge in environmental decision-making: challenges for deliberative democracy, Environment and Planning $A$

Reardon, K. (2003) Ceola's vision, our blessing: the story of an evolving communityuniversity partnership in East St. Louis, Illinois, in B. Eckstein and J. Throgorton (Eds) Story and Sustainability: planning, practice and possibility for American cities pp. 113-142. Cambridge, MA: MIT Press.

Rip, A. (2003) Constructing expertise: in a third wave of sciences studies?, Social Studies of Science 33(3), 419-434.

Rydin, Y. (2003a) Conflict, Consensus and Rationality in Environmental Planning: an institutional discourse approach. Oxford: Oxford University Press. Rydin, Y. (2003b) Urban and Environmental Planning in the UK. London: Palgrave. Sandercock, L.(1998) Towards Cosmopolis. London: Wiley. Tewdwr-Jones, M. \& Allmendinger, P. (1998) Deconstructing communicative rationality: a critique of Habermasian collaborative planning, Environment and Planning A (30), 1975-1989.

Ward, S. (2004) Planning and Urban Change. London: Sage.

Wenger, E. (1998) Communities of Practice: learning, meaning and identity. New York, NY: Cambridge University Press.

White, S. (1988) The Recent Work of Jurgen Habermas: Reason, justice and modernity. Cambridge: Cambridge University Press. 
Wynne, B. (1996) May the sheep safely graze? A reflexive view of the expert-lay knowledge divide, in B. Szerszynski, S. Lash and B. Wynne (Eds) Risk, Environment and Modernity: towards a new ecology, pp. 44 - 83. London: Sage.

Wynne, B. (2002) Risk and environment as legitimatory discourses of technology: reflexivity inside out, Current Sociology 50(3), 459-477.

Wynne, B. (2003) Seasick on the third wave? Subverting the hegemony of propositionalism, Social Studies of Science 33(3), 401-417. 
Table 1 A typology of planning knowledge claims: three examples

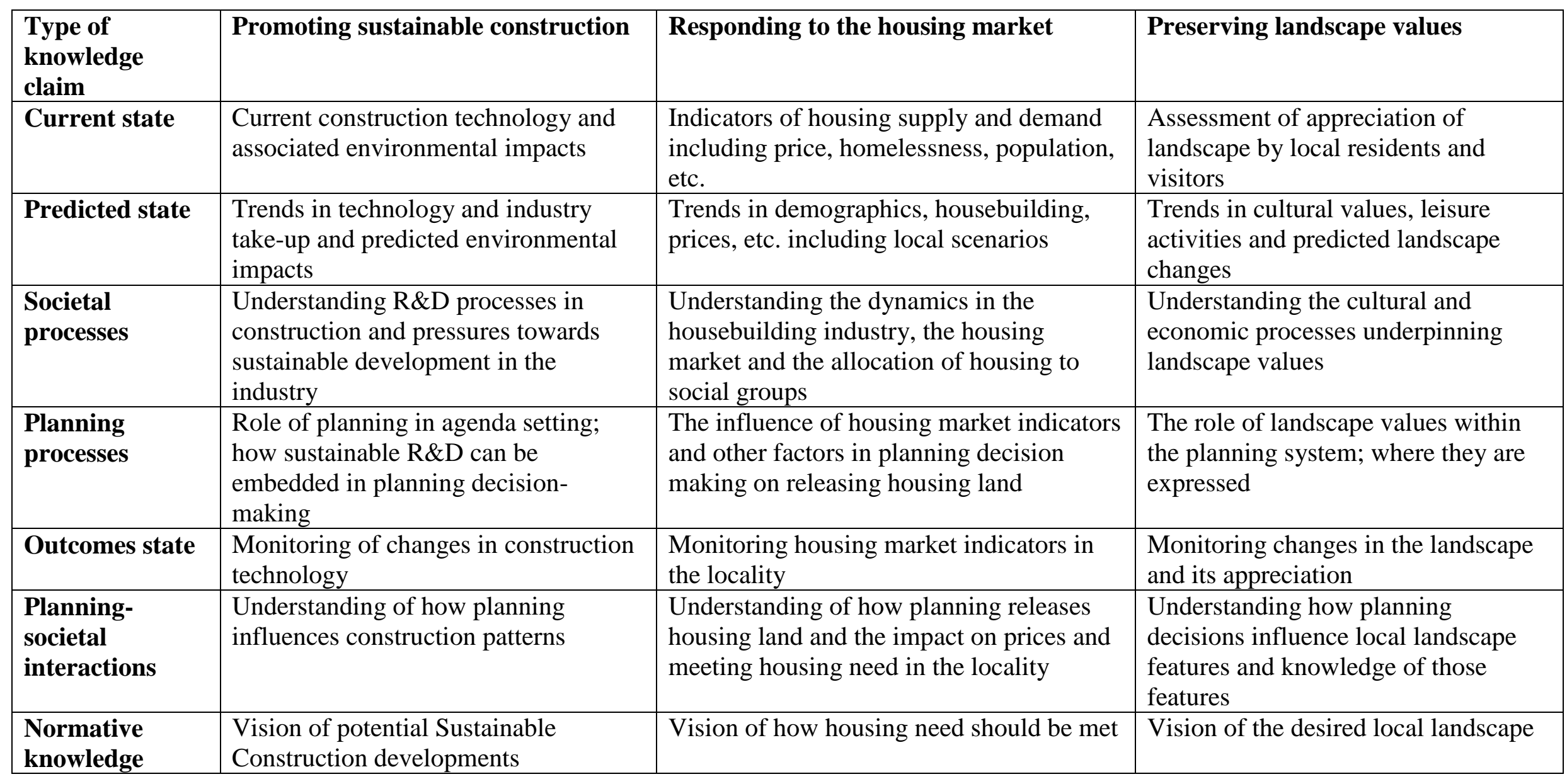


Table 2 Testing and recognising knowledge claims in planning

\begin{tabular}{|l|l|l|l|l|}
\hline $\begin{array}{l}\text { Type of } \\
\text { Knowledge }\end{array}$ & Empirical & Process & Predictive & Normative \\
\hline $\begin{array}{l}\text { Research } \\
\text { Method }\end{array}$ & $\begin{array}{l}\text { Variety of lay and expert modes } \\
\text { of engagement with material } \\
\text { circumstances }\end{array}$ & $\begin{array}{l}\text { Theoretically framed process } \\
\text { research; action research }\end{array}$ & $\begin{array}{l}\text { Theoretically framed } \\
\text { expert research on the } \\
\text { future informed by } \\
\text { experiential knowledge } \\
\text { where appropriate }\end{array}$ & $\begin{array}{l}\text { Informed debate in } \\
\text { the public sphere; } \\
\text { phronetic research }\end{array}$ \\
\hline $\begin{array}{l}\text { Relation of } \\
\text { planner to } \\
\text { research }\end{array}$ & $\begin{array}{l}\text { Mix of data analyst, } \\
\text { consultancy client and advocate } \\
\text { for lay perspectives }\end{array}$ & Object and/or participant in research & Consultancy client \\
\hline $\begin{array}{l}\text { Arena for } \\
\text { testing claims }\end{array}$ & $\begin{array}{l}\text { Forums for examining claims } \\
\text { and counter-claims and } \\
\text { resolving them; lay actors may } \\
\text { make and challenge claims with } \\
\text { planner support }\end{array}$ & $\begin{array}{l}\text { Testing involves debate between } \\
\text { causal models in academic and policy } \\
\text { contexts with lay and practitioner } \\
\text { input; planners judge the appropriate } \\
\text { mix of inputs in policy contexts }\end{array}$ & $\begin{array}{l}\text { As with process } \\
\text { knowledge but also } \\
\text { covering predictive } \\
\text { techniques }\end{array}$ & $\begin{array}{l}\text { Mediator; ethical } \\
\text { voice; informed voice }\end{array}$ \\
\hline $\begin{array}{l}\text { Role of } \\
\text { planner in } \\
\text { recognising } \\
\text { claims }\end{array}$ & $\begin{array}{l}\text { Planners draw account of } \\
\text { current situation from debates } \\
\text { deliberative means } \\
\text { with planner support }\end{array}$ & $\begin{array}{l}\text { Planners decide if causal model is } \\
\text { sufficiently robust for planning } \\
\text { decision-making }\end{array}$ & $\begin{array}{l}\text { As with process } \\
\text { knowledge but also } \\
\text { covering predictive } \\
\text { techniques }\end{array}$ & $\begin{array}{l}\text { Planners ensure the } \\
\text { possibility of } \\
\text { alternative futures is } \\
\text { considered }\end{array}$ \\
\hline
\end{tabular}

